\title{
Development and evaluation of recombinase-aided amplification assays incorporating competitive internal controls for detection of human adenovirus serotypes 3 and 7
}

Rui-huan Wang ${ }^{1,2,3+}$, Hong Zhang ${ }^{1,2^{*}+}$, Yi Zhang ${ }^{3 \dagger}$, Xin-na Li ${ }^{3}$, Xin-xin Shen ${ }^{3}, J u-j u ~ Q i^{3}$, Guo-hao Fan ${ }^{3}$, Xing-yu Xiang ${ }^{2}$, Zhi-fei Zhan ${ }^{2}$, Zi-wei Chen ${ }^{4}$ and Xue-jun $\mathrm{Ma}^{3^{*}}$

\begin{abstract}
Background: Human adenoviruses are a common group of viruses that cause acute infectious diseases. Human adenovirus (HAdV) 3 and HAdV 7 cause major outbreaks of severe pneumonia. A reliable and practical method for HAdV typing in clinical laboratories is lacking. A simple, rapid and accurate molecular typing method for HAdV may facilitate clinical diagnosis and epidemiological control.

Methods: We developed and evaluated duplex real-time recombinase-aided amplification (RAA) assays incorporating competitive internal controls for detection of HAdV 3 and HAdV 7, respectively. The assays were performed in a onestep in a single tube reaction at $39^{\circ}$ for $20 \mathrm{~min}$.

Results: The analytical sensitivities of the duplex RAA assays for HAdV 3 and HAdV 7 were 5.0 and 14.8 copies per reaction, respectively (at 95\% probability by probit regression analysis). No cross-reaction was observed with other types of HAdV or other common respiratory viruses. The duplex RAA assays were used to detect 152 previouslydefined HAdV-positive samples. These results agreed with those obtained using a published triplex quantitative realtime PCR protocol.

Conclusions: We provide the first report of internally-controlled duplex RAA assays for the detection of HAdV 3 and HAdV 7. These assays effectively reduce the rate of false negative results and may be valuable for detection of HAdV 3 and HAdV 7 in clinical laboratories, especially in resource-poor settings.
\end{abstract}

Keywords: Pneumonia, Human adenovirus, Duplex recombinase aided amplification, Detection

\footnotetext{
*Correspondence: $931525821 @ q q . c o m ;$ maxj@ivdc.chinacdc.cn

${ }^{\dagger}$ Rui-huan Wang, Hong Zhang and Yi Zhang contributed equally to this work.

${ }^{1}$ University of South China, College of Public Health, No. 28, West

Changsheng Street, Hengyang 421001, Hunan, China

${ }^{3} \mathrm{NHC}$ Key Laboratory of Medical Virology and Viral Diseases, National

Institute for Viral Disease Control and Prevention, Chinese Center for Disease

Control and Prevention, No. 155, Changbai Street, Changping District, Beijing

102206, China

Full list of author information is available at the end of the article
}

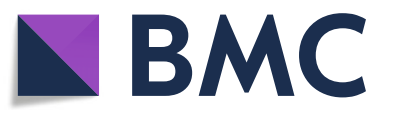

(c) The Author(s). 2019 Open Access This article is distributed under the terms of the Creative Commons Attribution 4.0 International License (http://creativecommons.org/licenses/by/4.0/), which permits unrestricted use, distribution, and reproduction in any medium, provided you give appropriate credit to the original author(s) and the source, provide a link to the Creative Commons license, and indicate if changes were made. The Creative Commons Public Domain Dedication waiver (http://creativecommons.org/publicdomain/zero/1.0/) applies to the data made available in this article, unless otherwise stated. 


\section{Background}

Human adenoviruses are non-enveloped, spherical, double-stranded DNA viruses belonging to the Adenoviridae family and the Mastadenovirus genus. Human adenovirus (HAdV) comprises of seven species (A-G), and $>90$ serotypes have been identified based on biophysical, biochemical and genetic characteristics (http:// hadvwg.gmu.edu/). HAdV is commonly detected in the pediatric population. Different serotypes of HAdV result in distinct clinical manifestations, including acute respiratory infections, conjunctivitis, pneumonia, gastroenteritis, myocarditis, and even central nervous system dysfunction $[1,2]$. Previous studies reported that HAdV 3 and HAdV 7 were the main genotypes causing outbreaks of infection in many countries [3], including Singapore, the United States, the United Kingdom, Korea [4] and Canada [2, 5]. In China, major outbreaks have happened in Taiwan [6], Chongqing [7] and Nanjing [8]. Deng Jie et al. [9] investigated acute respiratory infections among pediatric patients in Beijing, with HAdV 3 and HAdV 7 accounting for $>90 \%$ of infections. HAdV 3 and HAdV 7 were also the main causative pathogens of lower respiratory tract infection epidemics that caused fatalities $[10,11]$. Therefore, it is critical to develop sensitive and timely detection methods for HAdV 3 and HAdV 7, which may facilitate clinical diagnosis and epidemiological studies.

Traditional detection methods for HAdV 3 and HAdV 7 , such as immunoassays and viral culture [12], are not suitable for rapid disease diagnosis because they are time-consuming and laborious. Commonly used molecular diagnostic assays for the identificition HAdV 3 and HAdV 7 with high sensitivity and specificity, such as temperature switched amplification based on polymerase chain reaction (PCR) [13], fluorescence based real-time PCR [14, 15], and nested PCR [16], require a thermal cycler and well trained specialists, which is not practical for rapid and convenient detection in low income areas. Compared with traditional methods, isothermal nucleic acid amplifications methods such as loop mediated isothermal amplification (LAMP) [17] and nucleic acid sequence based amplification [18] are simple, rapid and cost-effective.

Here, we present a novel, isothermal, recombinaseaided amplification (RAA) assay which does not require a classical thermostable enzyme or a sophisticated thermal cycler. The enzymes used in the RAA assay include single strand DNA binding protein (SSB), recombinase UvsX, and DNA polymerase. The reaction is typically completed at $39^{\circ} \mathrm{C}$ in $20-30 \mathrm{~min}$. RAA has been successfully applied in the detection of bacterial and viral pathogens [19-21]. However, none of these methods included internal controls (ICs).An IC may be a competitive IC or a non-competitive IC. For a non-competitive IC, a set of primers is used for targeting the IC template, and a further set of primers is used for targeting the test template. However, different primers might have amplification bias and reduce the amplification efficiency of the target template. For a competitive IC, only one pair of primers is used in amplification, ensuring consistency of amplification. Occasionally, with an extremely high concentration of sample, amplification of the IC may be inhibited by competitive amplification. However, in such cases detection results are considered positive since the IC is only used to prevent false negative results [22]. The simultaneous amplification of two different DNA fragments from the same primer set may inhibit or enhance one or both of the products, depending on the molar ratio, length, sequence and secondary structure of the DNA fragments [23]. Therefore, the concentration of the IC used is important. The present study aimed to integrate RAA using fluorescence detection. We designed specific primers and probes and added a competitive IC as a quality control and thus established RAA assays for detection of HAdV 3 and HAdV 7 at $39^{\circ} \mathrm{C}$ in $20 \mathrm{~min}$. Additionally, we tested clinical samples and compared the performance of the RAA with a published triplex quantitative real-time PCR (tq-PCR) protocol [15].

\section{Results}

Singleplex RAA assay sensitivity and limit of detection

The sensitivity of singleplex RAA assays for HAdV 3 and HAdV 7 (i.e. containing samples but no IC) was determined using diluted recombinant standard plasmids. The detection limits of the singleplex RAA assays for HAdV 3 and HAdV 7 at $95 \%$ probability (probit analysis) were 4.4 and 5.0 copies/reaction, respectively (Table 1). No signal was detected for any of the negative controls.

\section{Duplex RAA assay sensitivity and specificity}

The optimum concentration of the IC template was determined to be $1 \times 10^{3}$ copies in each internally-controlled duplex RAA assay. This concentration did not inhibit amplification of 100 copies of the target gene (Fig. 1). The detection limits of the duplex RAA assays for HAdV 3 and HAdV 7 were 5.0 and 14.8 copies/reaction, respectively (Fig. 2; Table 1). As shown in Fig. 2, the higher the concentration of the virus target plasmid, the earlier the peak was observed, and the later the peak corresponding to the IC was observed. As shown in Table 1, results indicated that both HAdV 3 and HAdV 7 duplex RAA assays were capable of detecting 50 copies of the respective virus target per reaction.

A total of 64 other samples positive for common respiratory infections were respectively detected using the duplex RAA assays to test the specificity of the method. These pathogens included influenza A and B viruses, rhinovirus, parainfluenza virus, human bocavirus, coronavirus, human metapneumovirus, respiratory syncytial 
Table 1 Detection limits of HAdV 3 and HAdV 7 in singleplex and duplex RAA assays

\begin{tabular}{|c|c|c|c|c|}
\hline \multirow{3}{*}{$\begin{array}{l}\text { Copies/ } \\
\text { reaction }\end{array}$} & \multicolumn{4}{|c|}{ No. of positive samples/no. of samples tested by the RAA assay for detection of HAdV 3 and HAdV 7} \\
\hline & \multicolumn{2}{|c|}{ Singleplex RAA } & \multicolumn{2}{|c|}{ Duplex RAA } \\
\hline & HAdV 3 & HAdV 7 & HAdV 3 & HAdV 7 \\
\hline 1 copy/ML & $6 / 8$ & $2 / 8$ & $2 / 8$ & $0 / 8$ \\
\hline $10^{1} \mathrm{copy} / \mu \mathrm{L}$ & $8 / 8$ & $8 / 8$ & $8 / 8$ & $4 / 8$ \\
\hline $10^{2}$ copy/ $\mu \mathrm{L}$ & $8 / 8$ & $8 / 8$ & $8 / 8$ & $8 / 8$ \\
\hline $10^{3} \mathrm{copy} / \mu \mathrm{L}$ & $8 / 8$ & $8 / 8$ & $8 / 8$ & $8 / 8$ \\
\hline $10^{4}$ copy/ML & $8 / 8$ & $8 / 8$ & $8 / 8$ & $8 / 8$ \\
\hline
\end{tabular}

virus, and other HAdV species-A (HAdV 31), B (HAdV 14, 55), C (HAdV 1, 2, 5, 6, 57), and E (HAdV 4). No fluorescence signal was detected from any of these samples, indicating that the duplex RAA assays showed no cross-reactions with these pathogens (data not shown).

\section{Clinical evaluation of duplex RAA assays and agreement between duplex RAA assays and tq-PCR}

To evaluate the performance of the duplex RAA assays in the detection of HAdV 3 and HAdV 7, a total of 152 HAdV-positive clinical samples were detected with the duplex RAA assays. Tq-PCR results showed that there were 43 HAdV 3 samples and 58 HAdV 7 samples. A threshold cycle $(\mathrm{CT})$ value in tq-PCR $<38$ was considered a positive result. As shown in Fig. 3, the CT values of the HAdV 3 clinical samples ranged from 16.48 to 36.45 , and the CT values of the HAdV 7 samples ranged from 15.85 to 35.99 . The duplex RAA assays were able to detect weakly-positive specimens in tq-PCR, with CT values $>35$. Compared with tq-PCR (Table 2), the kappa values of the duplex RAA assays for HAdV 3 and HAdV 7 were $1.0(p<0.001)$ and $1.0(\mathrm{p}<0.001)$, respectively. That is, the results of tq-PCR and the duplex RAA assays were fully in agreement. However, the duplex RAA takes only $20 \mathrm{~min}$, while tq-PCR requires complex equipment and takes at least an hour.

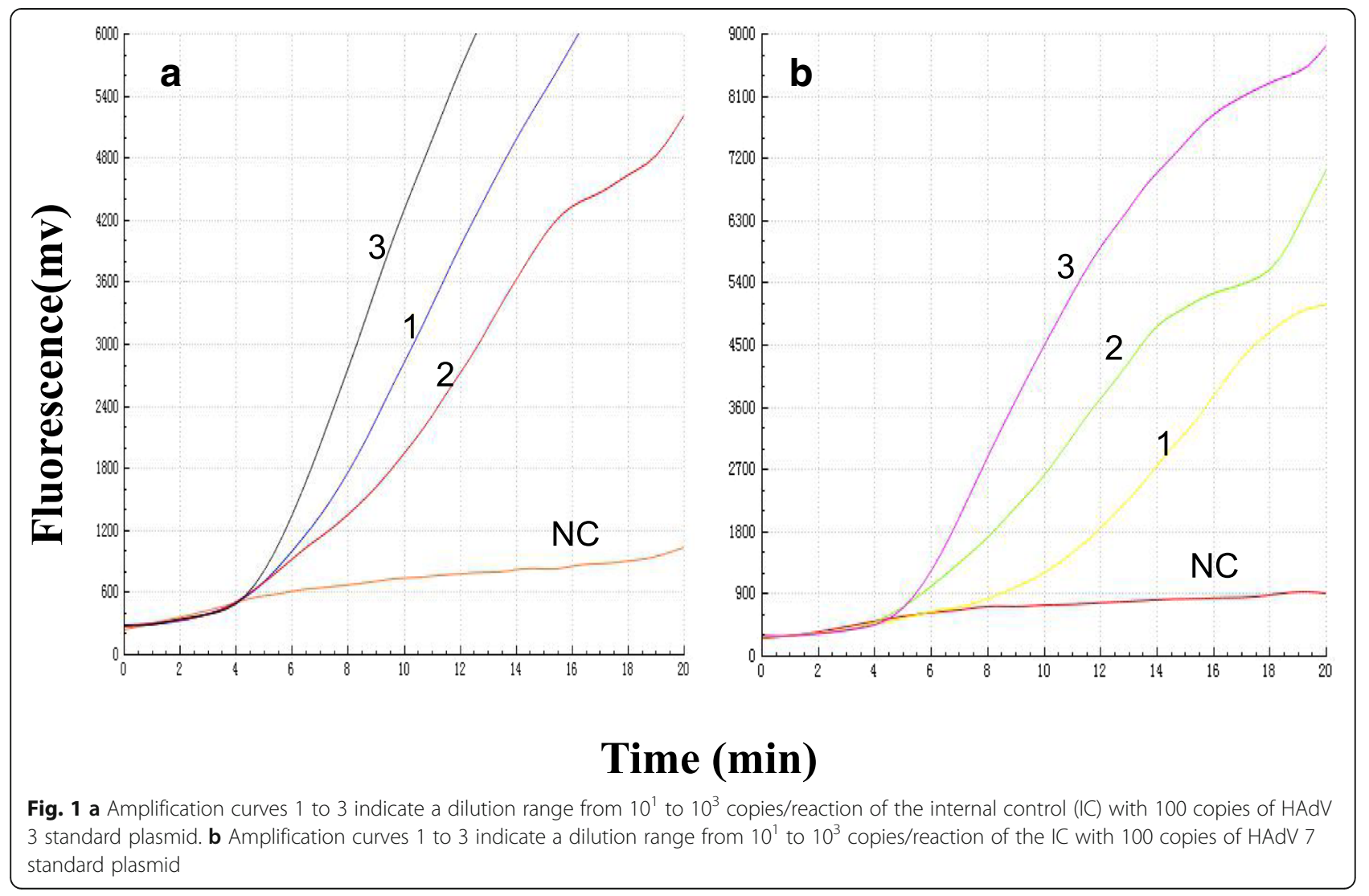




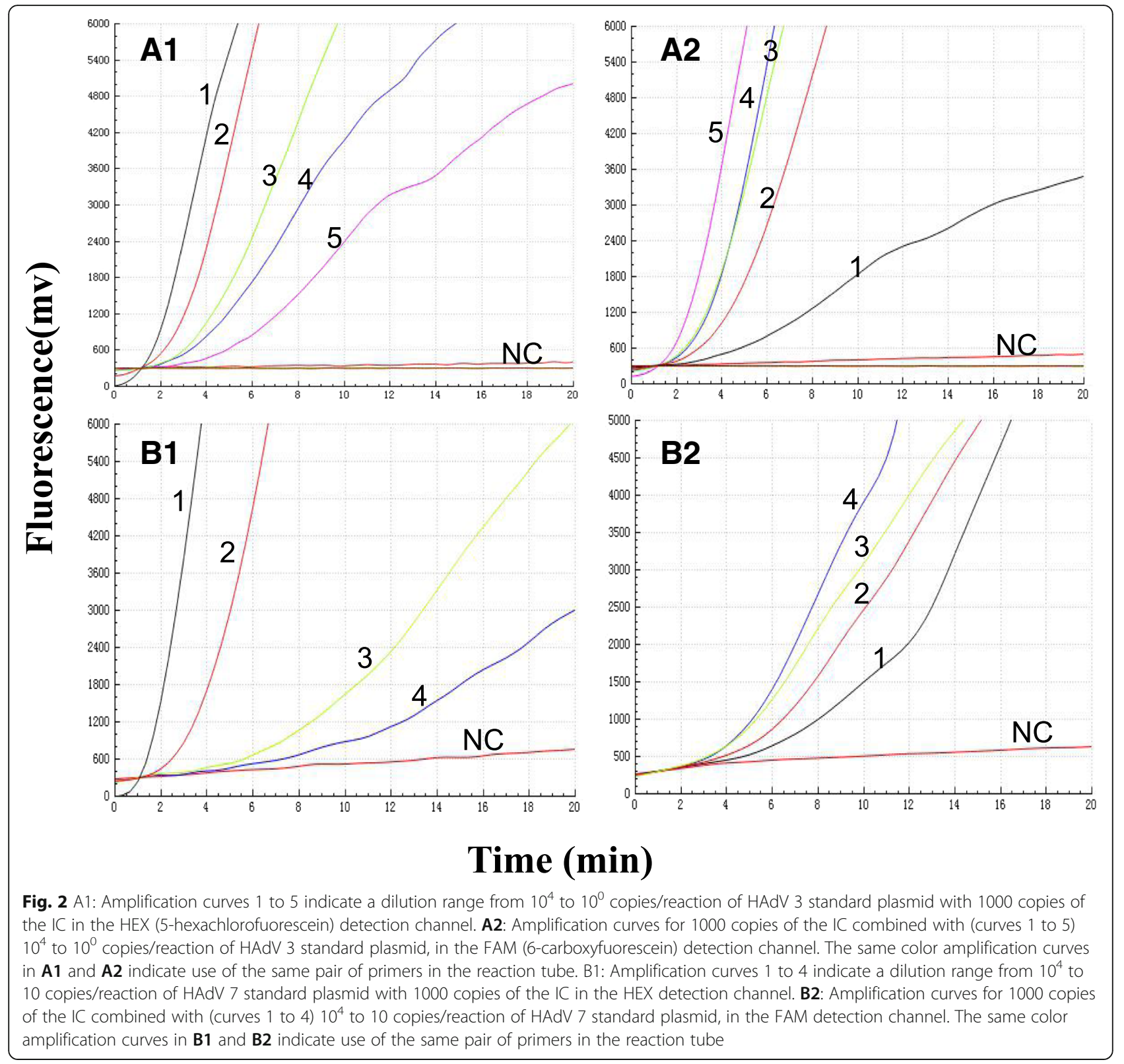

\section{Discussion}

HAdV 3 and HAdV 7 are serotypes responsible for worldwide severe HAdV infections [2, 12, 13], and may cause successive outbreaks of acute respiratory or central nervous system infection $[4,6,24]$. In China, epidemic outbreaks of HAdV 3 and HAdV 7 have been reported in Shanghai [25], Taiwan [6, 26], Nanjing [8], Beijing [9], and Chongqing [7]. Thus, a simple, rapid and accurate classification of HAdV 3 and HAdV 7 in HAdV detection is particularly desirable.

In this study, we first reported singleplex RAA assays for HAdV 3 and HAdV 7, respectively. Detection limits of these methods were 4.4 and 5.0 copies per reaction, respectively. These assays were further developed by introducing an IC to create two duplex real-time fluorescent RAA assays. The introduction of the IC effectively eliminated false negative results and invalid results.

Isothermal nucleic acid amplification assays including LAMP and RAA are increasingly used in virus detection $[17,19,21,27]$, but few studies have reported the use of an IC in isothermal assays. ICs are required to distinguish between true negative results and reactions that simply failed. Detection is considered negative when there is amplification of the IC only. If neither the IC nor the sample is amplified, an invalid assay is indicated [22]. As LAMP requires multiple primers, potential interaction between primers may lead to a difficult and complex situation for introducing an IC [28]. The RAA 


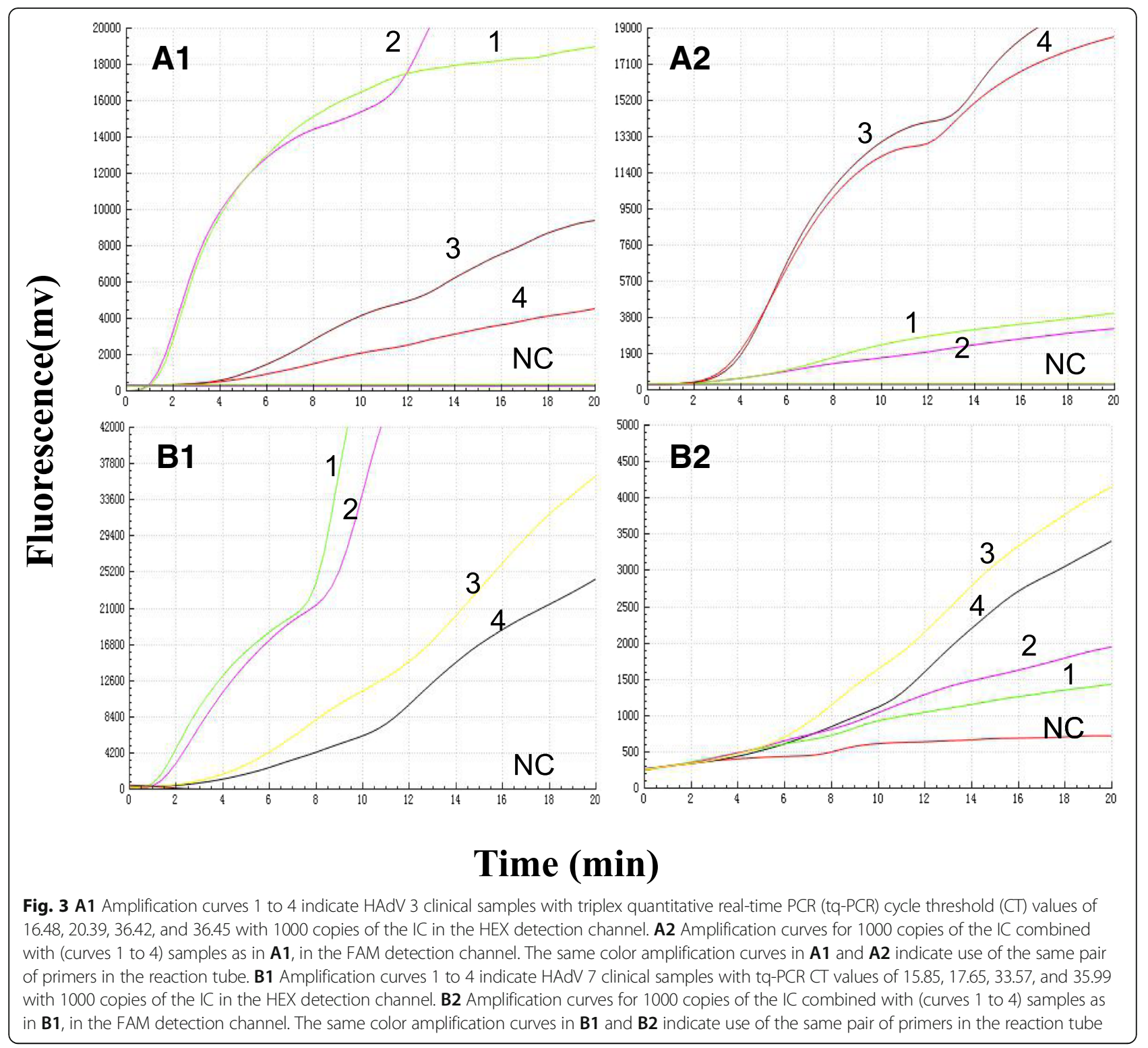

primer and probe are $>30 \mathrm{bp}$ in length, and long nucleic acid sequences easily form secondary structure, which is the major obstacle to developing a duplex RAA method including an IC.

In the present study, we adopted a competitive IC strategy with one pair of common primers in the same reaction tube. The only sequence difference between the target sequence and the IC sequence was in the probe binding region (Fig. 4). Using 100 copies of the target gene, we

Table 2 Detection of HAdV 3 and HAdV 7 in clinical samples

\begin{tabular}{lcccccc}
\hline Virus & \multicolumn{2}{l}{ Duplex RAA } & & tq-PCR & & Agreement \\
\cline { 2 - 3 } & Positive & Negative & & Positive & Negative & \\
\hline HAdV 3 & 43 & 0 & & 43 & 0 & $100 \%$ \\
HAdV 7 & 58 & 0 & & 58 & 0 & $100 \%$ \\
\hline
\end{tabular}

determined the optimum concentration of the IC as $1 \times$ $10^{3}$ copies. By optimizing the concentration of the IC template, we successfully established duplex RAA assays incorporating a competitive IC to avoid false negative results.

The duplex RAA detection limits of HAdV 3 and HAdV 7 were 5.0 and 14.8 copies per reaction (probit analysis, $p \leq 0.05$ ). Further application of the two methods to 48 HAdV 3-positive and 53 HAdV 7-positive clinical samples (identified by tq-PCR) showed $100 \%$ consistency of results. Seven samples that were weakly positive by tq-PCR (CT values $>35$ ) were identified as positive by the duplex RAA. In addition, no cross-reaction was observed with other common respiratory viruses or other HAdV species [A (HAdV 31), B (HAdV 14, 55), C (HAdV 1, 2, 5, 6, 57) or $\mathrm{E}$ (HAdV 4)] in clinical samples, indicating high sensitivity and specificity of the RAA. 


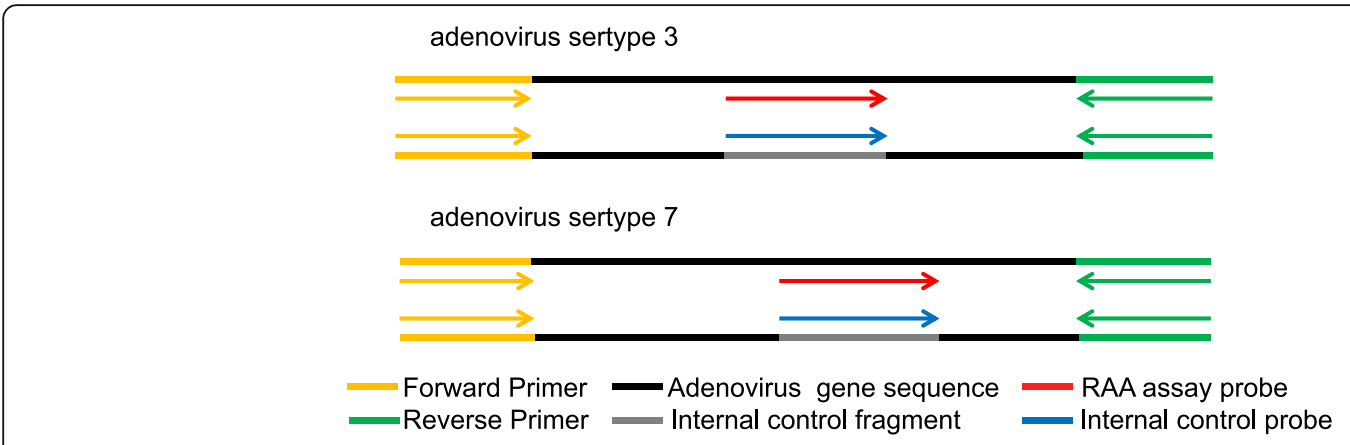

Fig. 4 Schematic diagram of duplex recombinase-aided amplification (RAA) assays for detection of HAdV 3 and HAdV 7

Compared with traditional PCR, the duplex RAA assay is convenient and fast $\left(20 \mathrm{~min}\right.$ at $\left.39^{\circ} \mathrm{C}\right)$ without the need for complicated operations or expensive variable-temperature PCR instrument. This assay was performed in a single closed tube, leading to a contamination-free test. The clinical samples tested with this assay were from two cities, one in southern China, the other in northern China, suggesting the adaptability of the duplex RAA assays for HAdV 3 and HAdV 7 detection.

More comprehensive evaluation of the duplex RAA assays using larger sets of clinical samples will be needed in the future. We will also attempt to combine the RAA with a lateral flow dipstick test for visual detection to avoid the need for a fluorescence detection device, and explore direct RAA detection of HAdV 3 and HAdV 7 by adding lytic solution to the original sample without nucleic acid extraction.

\section{Conclusions}

RAA assays for the detection of HAdV 3 and HAdV 7 with high sensitivity and specificity were demonstrated here. The method is rapid and does not require a thermal cycler. By introducing an IC, the duplex RAA assays successfully eliminated false negative results, thereby producing much more reliable tests. This method might have great potential for clinical use, especially in resource-poor settings.

\section{Materials and methods}

\section{Sample information}

A total of 256 clinical samples from patients with febrile respiratory syndrome were collected at the Hunan Provincial Center for Disease Control and Prevention and the Children's Hospital of Hebei Province (China) from 2014 to 2017, including 196 nasopharyngeal aspirates and 60 throat swabs. They were stored at $-80^{\circ} \mathrm{C}$ until extraction of nucleic acids. These specimens had previously been tested in a GeXP-based multiplex RT-PCR assay [29] for common respiratory viruses and 152 were found to be positive for HAdV. This study was conducted with the approval of the Institutional Review Boards of the National Institute for Viral Disease Control and Prevention, Center for Disease Control and Prevention of China. Written informed consent was obtained from children's caregivers.

\section{Nucleic acid extraction}

Total DNA was extracted from $200 \mu \mathrm{L}$ of each clinical sample using a Viral RNA/DNA Isolation Kit (Tianlong, Suzhou, China) according to the manufacturer's protocol. The DNA was eluted in $50 \mu \mathrm{L}$ of DNase- and RNase-free water and stored at $-80^{\circ} \mathrm{C}$ until use.

\section{Preparation of recombinant plasmids}

A 270-bp (nt 18,754-19,023, GenBank accession no. EF564601.1) and a 299-bp fragment (nt 18,486-18,784, GenBank accession no. KX897164.1) of the hexon genes of HAdV 3 and HAdV 7 were respectively cloned into vector pUC57 for DNA copy number quantification. The plasmid DNA was quantified using a Qubit 2.0 fluorometer (Life Technologies, Warrington, UK). The resulting DNA concentrations were converted to genome copy values using the formula:

DNA copy number (copy number $/ \mu \mathrm{L})=\left[6.02 \times 10^{14} \times\right.$ plasmid concentration $\left.(\mathrm{ng} / \mu \mathrm{L}) \times 10^{-9}\right] /[\mathrm{DNA}$ length in nucleotides $\times 660$ ].

The plasmids were diluted 10 -fold from $10^{8}$ to $10^{0}$ copies $/ \mu \mathrm{L}$, and stored at $-20^{\circ} \mathrm{C}$.

\section{Design of primers and probes}

Eighty complete hexon gene sequences of HAdV 3 and HAdV 7 were downloaded from NCBI GenBank, and the gene sequences were aligned using VectorNTI. Then the forward primer, reverse primer and probe were designed using Oligo7 according to the principle of minimizing secondary structure. Two RAA probes were also designed to target the IC templates for use in HAdV 3 and HAdV 7 duplex RAA assays. The IC template was a short gene sequence of rose rosette virus, which was inserted into the plasmids encoding HAdV 3 and HAdV 7 replacing the probe sequences of HAdV 3 and HAdV 7, 
Table 3 Primers and probes used for RAA and tq-PCR

\begin{tabular}{|c|c|c|c|c|}
\hline & Primer/probe & Sequence (5' to $3^{\prime}$ ) & Product size $(b p)$ & Source \\
\hline \multirow[t]{5}{*}{ RAA } & AdV 3-F & ATTCCGGCACAGCTTACAATTCACTCGCTCC & 184 & This paper \\
\hline & AdV 3-R & TCAGTAGTGG TAATGTCTTT CCCAATTTGC & & \\
\hline & AdV 3-Pa & $\begin{array}{l}\text { ACAATGCAGTAACTACCACCACAAACACA } \\
\text { [HEXdT][THF][BHQ-dT]GGCATTGCTTCCAT[C3-spacer] }\end{array}$ & & \\
\hline & AdV 7-F & ACAACGGGAGAAGACAATGCCACCACATACAC & 186 & Thispaper \\
\hline & $\begin{array}{l}\text { AdV 7-R } \\
\text { AdV 7-Pa } \\
\text { IC- } P^{a}\end{array}$ & $\begin{array}{l}\text { TCCATCAATATCAGTCCATGATTCTTCTCC } \\
\text { AAGACATTACTGCAGACAACAAGCCCATT } \\
\text { [HEXdT]THH][BHQ-dT]GCCGATAAAACATAT[C3-spacer] } \\
\text { GTAAGGTGCTAGACTAAAATTGTTGGGACTT } \\
\text { [FAMdT]GTHF]A[BHQ-dT]CTCTGAAGTAAAAGG[C3-spacer] }\end{array}$ & & \\
\hline \multirow[t]{4}{*}{ tq-PCR } & F-primer & GGYCCYAGYTTYAARCCCTAYTC & & [15] \\
\hline & R-primer & AAYTTGAGGYTCTGGYTGATCKG & & \\
\hline & Probe3 & HEX-ACAATGCAGTAACTACCACCACAA-MGB & & \\
\hline & Probe7 & Cy5-TTACTGCAGACAACAAGCCCAT-MGB & & \\
\hline
\end{tabular}

'Probe modifications: FAM 6-carboxyfuorescein, HEX 5-hexachlorofuorescein, THF Tetrahydrofuran, BHQ Black hole quencher, C3-spacer 3' phosphate blocker

respectively (Fig. 4). The cloning was conducted by TsingKe Biotech Corp. (Beijing, China). The HAdV probes and IC probes were labelled with 5-hexachlorofuorescein (HEX) and 6-carboxyfuorescein (FAM) fluorophores, respectively. All the primer and probe sequences are listed in Table 3. The primers and probes were synthesized by Shanghai Bioengineering (Shanghai, China).

\section{Singleplex RAA assay protocol, analytical sensitivity and limit of detection}

The singleplex real time RAA assay was performed in a $50-\mu \mathrm{l}$ reaction volume using the RAA exo kit (Jiangsu Qitian Bio-Tech Co. Ltd., China). The reaction components included $25 \mu \mathrm{L}$ rehydration buffer, $16.7 \mu \mathrm{L}$ DNase-free water, $2.1 \mu \mathrm{L}$ of $10 \mu \mathrm{M}$ forward and reverse primers, $0.6 \mu \mathrm{L}$ of $10 \mu \mathrm{M}$ target specific RAA exo-probe, and $1 \mu \mathrm{L}$ DNA template or $1 \mu \mathrm{L}$ DNase-free water. The $47.5-\mu \mathrm{L}$ reaction mixture was added to the lyophilized RAA pellet kit which contains all necessary enzymes (SSB, $800 \mathrm{ng} / \mu \mathrm{L}$; UvsX, $120 \mathrm{ng} / \mu \mathrm{L}$; DNA polymerase, $30 \mathrm{ng} / \mu \mathrm{L}$ ), then $2.5 \mu \mathrm{L}$ of $280 \mathrm{mM}$ magnesium acetate were pipetted into the caps. The tube lids were carefully sealed and the tubes were shaken and centrifuged by vortex instrument for $4 \mathrm{~min}$. Then, the tubes were transferred to the tube holder on the QT-RAA-F1620 real-time fluorescence detection system (Jiangsu Qitian Bio-Tech Co. Ltd.) at $39^{\circ} \mathrm{C}$ for $20 \mathrm{~min}$. The RAA assay sensitivity for detection of HAdV 3 and HAdV 7 was determined using 10-fold dilutions of recombinant standard plasmid $\left(10^{4}\right.$ to $10^{\circ}$ copies per reaction, $n=8)$. Negative control reactions were performed in parallel in each run.

\section{Development of internally-controlled duplex RAA assays} The HAdV 3 and HAdV 7 singleplex RAA assays were further developed to establish internally-controlled duplex
RAA assays by incorporating an IC template and corresponding exo probe. The real-time RAA reaction was performed in a $50-\mu \mathrm{L}$ volume using the exo kit (Jiangsu Qitian Bio-Tech Co. Ltd.): $25 \mu \mathrm{L}$ rehydration buffer, 15.1 $\mu \mathrm{L}$ DNase-free water, $2.1 \mu \mathrm{L}$ of forward and reverse primers $(10 \mu \mathrm{M}), 0.6 \mu \mathrm{L}$ of target specific exo probe $(10 \mu \mathrm{M}), 0.6 \mu \mathrm{L}$ of IC exo probe $(10 \mu \mathrm{M}), 1 \mu \mathrm{L}$ IC template, $1 \mu \mathrm{L}$ DNA template or $1 \mu \mathrm{L}$ DNase-free water, and $2.5 \mu \mathrm{L}$ of $280 \mathrm{mM}$ magnesium acetate. The specific reaction steps were performed as described for the singleplex RAA reactions. The optimum concentration of the IC template was evaluated by testing 100 copies of target plasmids in the presence of various IC copy concentrations $\left(1 \times 10,1 \times 10^{2}, 1 \times 10^{3}\right)$. Standard recombinant plasmids with a dilution range $10^{4}-0^{0}$ were prepared to determine the sensitivity of duplex RAA assays for detection of HAdV 3 and HAdV 7, respectively. The method of determination of sensitivity and the limit of detection was as described above. Specificity was evaluated by retrospective testing of 64 samples positive for other respiratory viruses or other types of HAdV.

\section{Evaluation of the duplex RAA assays using clinical samples and comparison with tq-PCR}

To evaluate the clinical performance, a total of 152 clinical samples previously confirmed HAdV-positive by a GeXP-based multiplex RT-PCR assay were nucleic acid extracted again, then detected in duplicate by the duplex RAA assays. A reference tq-PCR assay for the detection of HAdV 3 and HAdV 7, respectively, was performed in parallel on these samples. A tq-PCR threshold cycle (CT) value of $<38$ was determined as a positive result. A slope of the RAA amplification curve $>20$ set by the detection device was determined as positive. 


\section{Abbreviations}

HAdV: Human adenovirus; IC: Internal control; PCR: Polymerase chain reaction; RAA: Recombinase-aided amplification; tq-PCR: Triplex quantitative real-time $P C R$

\section{Acknowledgements}

We acknowledge Hunan Provincial Center for Disease Control and Prevention and the Children's Hospital of Hebei Province, China, for providing clinical specimens.

\section{Funding}

This work was supported by grants from the China Mega-Projects for Infectious Disease (2018ZX10711001, 2017ZX10104001 and 2018ZX10713002), and the Key R \& D Program of Hunan Province (2017SK2101)

\section{Availability of data and materials}

The datasets used and/or analyzed during the current study are available from the corresponding author on reasonable request.

\section{Authors' contributions}

XJM and $\mathrm{HZ}$ conceived the study. XYX, ZFZ and ZWC conducted the collection of specimens. RHW, YZ, XNL, XXS, JJQ and GHF performed experiments. RHW wrote this article, XJM revised it. All authors have read and approved the final version of the manuscript.

\section{Ethics approval and consent to participate}

All aspects of the study were performed in accordance with national ethics regulations and approved by the Institutional Review Boards of the National Institute for Viral Disease Control and Prevention, Center for Disease Control and Prevention of China.

\section{Consent for publication}

Not applicable.

\section{Competing interests}

All the authors approved the final manuscript and they have no competing interests to declare.

\section{Publisher's Note}

Springer Nature remains neutral with regard to jurisdictional claims in published maps and institutional affiliations.

\section{Author details}

${ }^{1}$ University of South China, College of Public Health, No. 28, West Changsheng Street, Hengyang 421001, Hunan, China. ${ }^{2}$ Hunan Provincial Center for Disease Control and Prevention, No. 450, Furong Street, Changsha 410005, Hunan, China. ${ }^{3} \mathrm{NHC}$ Key Laboratory of Medical Virology and Viral Diseases, National Institute for Viral Disease Control and Prevention, Chinese Center for Disease Control and Prevention, No. 155, Changbai Street, Changping District, Beijing 102206, China. ${ }^{4}$ The Third Xiangya Hospital of Central South University, 138 Tongzipo Road, Yuelu District, Changsha City 410013, Hunan Province, China.

\section{Received: 15 March 2019 Accepted: 14 May 2019}

Published online: 01 July 2019

\section{References}

1. Huang YC, Huang SL, Chen SP, Huang YL, Huang CG, Tsao KC, Lin TY. Adenovirus infection associated with central nervous system dysfunction in children. J Clin Virol. 2013;57:300-4.

2. Lynch JP 3rd, Kajon AE. Adenovirus: epidemiology, global spread of novel serotypes, and advances in treatment and prevention. Semin Respir Crit Care Med. 2016;37:586-602

3. Abbas KZ, Lombos E, Duvvuri VR, Olsha R, Higgins RR, Gubbay JB. Temporal changes in respiratory adenovirus serotypes circulating in the greater Toronto area, Ontario, during December 2008 to April 2010. Virol J. 2013:10:15.

4. Lee WJ, Jung HD, Cheong HM, Kim K. Molecular epidemiology of a postinfluenza pandemic outbreak of acute respiratory infections in Korea caused by human adenovirus type 3. J Med Virol. 2015;87:10-7.
5. Alharbi S, Van Caeseele P, Consunji-Araneta R, Zoubeidi T, Fanella S, Souid AK, Alsuwaidi AR. Epidemiology of severe pediatric adenovirus lower respiratory tract infections in Manitoba, Canada, 1991-2005. BMC Infect Dis. 2012:12:55.

6. Chang SY, Lee CN, Lin PH, Huang HH, Chang LY, Ko W, Chang SF, Lee PI, Huang LM, Kao CL. A community-derived outbreak of adenovirus type 3 in children in Taiwan between 2004 and 2005. J Med Virol. 2008;80:102-12.

7. Wo Y, Lu QB, Huang DD, Li XK, Guo CT, Wang HY, Zhang XA, Liu W, Cao WC. Epidemical features of HAdV-3 and HAdV-7 in pediatric pneumonia in Chongqing, China. Arch Virol. 2015;160:633-8.

8. Gao XQ, Jin Y, Xie ZP, Gao HC, Xie LY, Zhang J, Duan ZJ. The epidemiological study of adenovirus in children with respiratory tract infections in Nanjing area from 2010 to 2011. Bing Du Xue Bao. 2012;28:531-5.

9. Deng J, Qian Y, Zhao LQ, Zhu RN, Wang F, Sun Y, Liao B, Huang RY, Yuan Y, Qu D, Ren XX. Identification and typing of adenoviruses from pediatric patients with acute respiratory infections in Beijing from 2003 to 2008. Zhonghua Er Ke Za Zhi. 2010;48:739-43.

10. Kim YJ, Hong JY, Lee HJ, Shin SH, Kim YK, Inada T, Hashido M, Piedra PA. Genome type analysis of adenovirus types 3 and 7 isolated during successive outbreaks of lower respiratory tract infections in children. J Clin Microbiol. 2003:41:4594-9.

11. Moro MR, Bonville CA, Suryadevara M, Cummings E, Faddoul D, Kobayaa H, Branigan PJ, Domachowske JB. Clinical features, adenovirus types, and local production of inflammatory mediators in adenovirus infections. Pediatr Infect Dis J. 2009;28:376-80.

12. Lee J, Choi EH, Lee HJ. Comprehensive serotyping and epidemiology of human adenovirus isolated from the respiratory tract of Korean children over 17 consecutive years (1991-2007). J Med Virol. 2010;82:624-31.

13. Echavarria M, Forman M, Ticehurst J, Dumler JS, Charache P. PCR method for detection of adenovirus in urine of healthy and human immunodeficiency virus-infected individuals. J Clin Microbiol. 1998;36:3323-6.

14. Chmielewicz B, Nitsche A, Schweiger B, Ellerbrok H. Development of a PCRbased assay for detection, quantification, and genotyping of human adenoviruses. Clin Chem. 2005;51:1365-73.

15. Qiu FZ, Shen XX, Zhao MC, Zhao L, Duan SX, Chen C, Qi JJ, Li GX, Wang L, Feng ZS, Ma XJ. A triplex quantitative real-time PCR assay for differential detection of human adenovirus serotypes 2, 3 and 7. Virol J. 2018;15:81.

16. Zhao L, Wang J, Li GX, Qiu FZ, Chen C, Zhao MC, Wang L, Duan SX, Feng ZS, Ma XJ. A highly sensitive 1-tube nested real-time RT-PCR assay using LNA-modified primers for detection of respiratory syncytial virus. Diagn Microbiol Infect Dis. 2019;93:101-6.

17. Li F, Zhao LQ, Deng J, Zhu RN, Sun Y, Liu LY, Li YY, Qian Y. Detecting human adenoviruses in respiratory samples collected from children with acute respiratory infections by loop-mediated isothermal amplification. Zhonghua Er Ke Za Zhi. 2013:51:52-7.

18. Lanciotti RS. Molecular amplification assays for the detection of flaviviruses. Adv Virus Res. 2003:61:67-99.

19. Yan TF, Li XN, Wang L, Chen C, Duan SX, Qi JJ, Li LX, Ma XJ. Development of a reverse transcription recombinase-aided amplification assay for the detection of coxsackievirus A10 and coxsackievirus A6 RNA. Arch Virol. 2018; 163:1455-61.

20. Duan S, Li G, Li X, Chen C, Yan T, Qiu F, Zhao L, Zhao M, Wang L, Feng Z, Ma X. A probe directed recombinase amplification assay for detection of MTHFR A1298C polymorphism associated with congenital heart disease. Biotechniques. 2018:64:211-7.

21. Chen C, Li XN, Li GX, Zhao L, Duan SX, Yan TF, Feng ZS, Ma XJ. Use of a rapid reverse-transcription recombinase aided amplification assay for respiratory syncytial virus detection. Diagn Microbiol Infect Dis. 2018;90:90-5.

22. Higgins O, Clancy E, Forrest MS, Piepenburg O, Cormican M, Boo TW, O'Sullivan N, McGuinness C, Cafferty D, Cunney R, Smith TJ. Duplex recombinase polymerase amplification assays incorporating competitive internal controls for bacterial meningitis detection. Anal Biochem. 2018;546:10-6.

23. Hoorfar J, Malorny B, Abdulmawjood A, Cook N, Wagner M, Fach P. Practical considerations in design of internal amplification controls for diagnostic PCR assays. J Clin Microbiol. 2004;42:1863-8.

24. Adhikary AK. Genomic diversity of human adenovirus type 3 isolated in Fukui, Japan over a 24-year period. J Med Microbiol. 2017;66:1616-22.

25. Lu L, Zhong H, Su L, Cao L, Xu M, Dong N, Xu J. Detection and molecular characterization of human adenovirus infections among hospitalized children with acute diarrhea in Shanghai, China, 2006-2011. Can J Infect Dis Med Microbiol. 2017;2017:9304830. 
26. Lin YC, Lu PL, Lin KH, Chu PY, Wang CF, Lin JH, Liu HF. Molecular epidemiology and phylogenetic analysis of human adenovirus caused an outbreak in Taiwan during 2011. PLoS One. 2015;10:e0127377.

27. Chen L, Fan XZ, Wang Q, Xu L, Zhao QZ, Zhou YC, Liu J, Tang B, Zou XQ. A novel RT-LAMP assay for rapid and simple detection of classical swine fever virus. Virol Sin. 2010;25:59-64.

28. Watts MR, James G, Sultana Y, Ginn AN, Outhred AC, Kong F, Verweij JJ, Iredell JR, Chen SC, Lee R. A loop-mediated isothermal amplification (LAMP) assay for Strongyloides stercoralis in stool that uses a visual detection method with SYTO-82 fluorescent dye. Am J Trop Med Hyg. 2014;90:306-11.

29. Li J, Qi S, Zhang C, Hu X, Shen H, Yang M, Wang J, Wang M, Xu W, Ma X. A two-tube multiplex reverse transcription PCR assay for simultaneous detection of sixteen human respiratory virus types/subtypes. Biomed Res Int. 2013;2013:327620.

Ready to submit your research? Choose BMC and benefit from:

- fast, convenient online submission

- thorough peer review by experienced researchers in your field

- rapid publication on acceptance

- support for research data, including large and complex data types

- gold Open Access which fosters wider collaboration and increased citations

- maximum visibility for your research: over $100 \mathrm{M}$ website views per year

At $\mathrm{BMC}$, research is always in progress.

Learn more biomedcentral.com/submissions 